
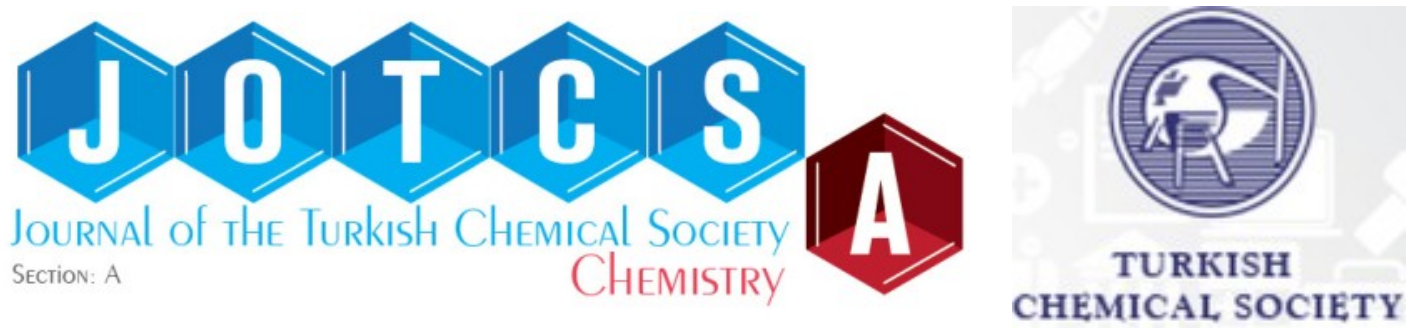

\title{
Residual Determination of Multiple Pesticides in Vegetable Samples by LC-MS/MS Coupled with Modified QuEChERS-dSPE Ionic Liquid-Based DLLME Method
}

\author{
Abubakar Lawal ${ }^{1,2 *}$ (D) and Kah Hin Low ${ }^{1}$ \\ ${ }^{1}$ Department of Chemistry, University of Malaya, Kuala Lumpur, Malaysia. \\ ${ }^{2}$ Department of Pure and Industrial Chemistry, Umaru Musa Yar'adua University Katsina, Nigeria.
}

\begin{abstract}
As a matter of fact, the Dietary Guidelines of the United States of America recommended the consumption of more fruits and vegetables to support the healthy condition of the body. Unfortunately, these food materials are being accumulated with pesticidal residues due to the continuous missmanagement and excessive application of the chemicals during pre and post-agricultural practices, which compels multiple analysis of pesticidal residues to know their concentration levels for the betterment of food security and safety. For that matter, multi-residues of Thiamethoxam, Propamocarb, Carbaryl, Metalaxyl, Baycarb, Thiobencarb, Diazinon, and Dursban pesticides were determined in the samples of lettuce, garlic, ginger, and bell-pepper using modified QuEChERS-dSPE Ionic Liquid-based dispersive liquid-liquid microextraction (DLLME) method coupled with LC-MS/MS instrument and validated (European Union Guideline). Resultantly, the accuracy (87-127\%) and precision (0-22\%) were mostly within the acceptable range for the former (70-120\%) and latter $(\leq 20 \%)$. Meanwhile, the limit of detections $(0.01-0.28 \mu \mathrm{g} / \mathrm{kg}$ ) and limit of quantitations $(0.03-0.93 \mu \mathrm{g} / \mathrm{kg})$ were satisfactory. The concentration range $(5-400 \mu \mathrm{g} / \mathrm{kg}$ ) of calibration curves for the evaluated linearity were linear with coefficient of regressions greater than 0.99 . The matrix effects for all the analyzed samples were very weak and less effective $(\leq-86 \%)$. The range $(1-25 \%)$ for the estimated measurement uncertainties were certifiable and acceptable $(\leq 50 \%)$. Therefore, the sample preparation method prove effective as validated and useful for the multiple determination of pesticides residues in the analyzed vegetable samples, which are presumably safe for consumption against health issues.
\end{abstract}

Keywords: Pesticide residues; fruits and vegetables; QuEChERS-dSPE and DLLME cleanups; ionic liquidbased; liquid chromatography tandem mass spectrometry.

Submitted: December 24, 2020. Accepted: May 20, 2021.

Cite this: Lawal A, Low KH. Residual Determination of Multiple Pesticides in Vegetable Samples by LCMS/MS Coupled with Modified QuEChERS-dSPE Ionic Liquid-Based DLLME Method. JOTCSA. $2021 ; 8(2): 693-704$.

DOI: https://doi.org/10.18596/jotcsa.845578.

*Corresponding Author. E-mail: abubakarlawal360@yahoo.com.

\section{INTRODUCTION}

Fruit and vegetable foods are one of the bases that constitute healthy diets worldwide, playing vital roles nutritionally for the attainment of a healthy life (1). Moreover, fresh fruits and vegetables provide dietary fibers, carbohydrate, vitamins (particularly vitamin C), minerals (particularly electrolytes), and bioactive compounds (2-4). The bioactive compounds include phytochemicals, which possesses antioxidant, phytoestrogen activities and anti-inflammatory agents $(5,6)$. Moreover, the dietary fibers supplied by these foods prevent gastrointestinal cancers and contribute to lowering the cholesterol level in the blood (cholesterolemia) (7). Consequently, reducing the high peril of cardiovascular diseases and the reduction of high risks of obesity $(8,9)$. 
Meanwhile, the derived nutrients and biological compounds in fruits and vegetables depend on nature, size, geographical locations they were cultivated (10). In the year 2010, it was recommended by the Dietary Guidelines of the United States of America suggested that one-half of a person's plate of food should contain fruits and vegetables (11). Unfortunately, the percentage of nutrients in fruits and vegetables has been decreasing over the years due to soil depletion of essential materials caused by intensive modern agricultural techniques $(12,13)$, which results in consumption of more fruits and vegetables to support the healthy condition of the body (11).

Notwithstanding, the fresh vegetables and fruits of today have been accumulated with pesticide residues because of the continuous missmanagement and excessive application of pesticides during pre and post-agricultural practices (14-17). For example, the triazole fungicides, carbamates, pyrethroids, and organochlorine pesticides (OCPs) are most wellknown for controlling pests in vegetables and fruits (18-20). This could lead to disastrous healthrelated issues such as different forms of cancer and congenital disabilities (1). Based on these facts, the food quality controllers and the analytical scientists have periodically analyzed the concentration levels of pesticides residue in vegetable and fruit samples using conventional methods and instruments such as gas and liquid chromatography.

Illustratively, the conventional methods include liquid-liquid extraction (LLE), solid phase extraction (SPE) and liquid phase microextraction (LPME) (20). Unfortunately, most of the methods possess poor selectivity. Meanwhile, many detectors such as diode array, photodiode array and mass spectrometry instrumentally possesses poor sensitivity towards targeted analytes because most of the instruments were operated at default settings lacking optimization (21). Fortunately, the recent reports suggested the use of a modified quick, easy, cheap, effective, rugged, and safe (QuEChERS)-dispersive SPE (dSPE) coupled with LPME as dispersive liquid-liquid microextraction (DLLME) technique instrumented with an optimized liquid chromatography tandem mass spectrometry (LC-MS/MS) for analysis of multiple pesticidal residues in fruits and vegetables $(15,21)$. Also, the optional used of 1-hexyl-3-methylimidazolium hexafluorophosphate $\left(\left[\mathrm{C}_{6} \mathrm{MIM}\right]\left[\mathrm{PF}_{6}\right]\right)$ ionic liquidbased in the DLLME technique increases the extraction efficiency and chromatographic properties of the analysis $(22,23)$.

Therefore, this study was aimed to determine the multi-pesticide residues of Thiamethoxam, Propamocarb, Carbaryl, Metalaxyl, Baycarb,
Thiobencarb, Diazinon, and Dursban (Figure 1) in some selected sample of vegetables. The analyses were carried out using the modified QuEChERSdSPE Ionic Liquid-based DLLME coupled with optimized LC-MS/MS method revealed by Lawal et al. (15) and Lawal, et al. (21). It is hoped that this study will serve as a reference guide for the future studies of pesticide residues in other vegetable samples to provide betterment of food security and safety.

\section{MATERIALS AND METHODS}

\section{Chemicals and Reagents}

The pesticidal standards $(100 \mathrm{mg} / \mathrm{kg})$ for Thiamethoxam, Propamocarb, Carbaryl, Metalaxyl, Baycarb, Thiobencarb, Diazinon, and Dursban were obtained from AccuStandard ${ }^{\circledR}$ (New Haven, USA) and were later diluted to $0.1 \mathrm{mg} / \mathrm{kg}(100 \mu \mathrm{g} / \mathrm{kg})$ with estimated volume of methanol, respectively. Meanwhile, the LC-MS grade organic solvents were used for this research work. The solvents include methanol and ACN (Merck, Germany), acetic acid $(\mathrm{HOAc})$, and formic acid were obtained from Fisher Scientific. The Millipore-filtered (deionized) water was obtained using Merck Millipore water purification system (Billerica, USA). The ProElut ${ }^{\mathrm{TM}}$ AOAC 2007.01 QuEChERS-dSPE kits for general vegetables and fruits were obtained from Dikma Technologies Inc. (Lake Forest, USA), as well as the molten salt (HPLC grade) of [ $\left.\mathrm{C}_{6} \mathrm{MIM}\right]\left[\mathrm{PF}_{6}\right]$ ionic liquid-based $(P \geq 97.0 \%)$ was purchased from Sigma-Aldrich, (Germany).

\section{Apparatus and Equipments}

The 2, 15, and $50 \mathrm{~mL}$ polypropylene centrifuge tubes by LabServ Fisher-Scientific (Kuala Lumpur, Malaysia), and 100 and $500 \mu \mathrm{L}$ microsyringes were obtained from Agilent (Australia). The HPLC autosampler vials were purchased from Agilent Technologies (USA) and other equipments such as Dynamica refrigerated centrifuge by CNG instruments (Selangor, Malaysia), vortexer VTX3000L by Copens Scientific (Tokyo, Japan) and glass jug blender MX-GX1581WSK (Panasonic, Malaysia) and Supelco HPLC column [Ascentis ${ }^{\circledR}$ Express $\mathrm{C}_{18}(5 \mathrm{~cm} \times 2.1 \mathrm{~mm}, 2.7 \mu \mathrm{m})$ ] (SigmaAldrich, USA). The others include weighing balance (Sartorius Technology Park, Germany), pH meter PB (Sartorius group, Germany) and Agilent triple quadrupole LC/MS G6490A [built in Electrosprays ESI $( \pm)$ MS/MS Sensitivity and Jet stream Technology] instrument (Singapore).

\section{Conditioning the LC-MS/MS Instrument}

The setup for contributory factors of the LC-MS/MS instrument were optimized. These include; analyte injection volume $(5 \mu \mathrm{L})$, column temperature (30 $\left.{ }^{\circ} \mathrm{C}\right)$, flow rate $(0.1 \mathrm{~mL} / \mathrm{min})$, gas temperature (200 $\left.{ }^{\circ} \mathrm{C}\right)$, gas flow (14 L/min), nebulizer gas (45 psi), sheath gas temperature $\left(400^{\circ} \mathrm{C}\right)$, sheath gas flow 
(11 L/min), capillary voltage $(3000 \mathrm{~V})$ and delta ${ }^{(+)}$ EMV $(200 \mathrm{~V})$. The factors were used for the determination of optimum fragmentary voltage and the four-fragmentary product ions with their respective retention time (RT) and collision energy $(\mathrm{CE})$ by the Auto-tuning and Mass-Hunter instrumental optimization using $1 \mathrm{mg} / \mathrm{kg}$ multipesticides mixture of standard solutions (Table 1) and the total ion chromatography (TIC) were highlighted (Figure 2). Moreover, the setup was also used for the estimated gradient (elution) time for the mobile phase-B at 15\% (0 - $1.6 \mathrm{~min}), 15-$ $100 \%$ (1.6 - $10.4 \mathrm{~min})$, and $100-15 \%$ (10.4 - 12 $\mathrm{min})$ at the pressure of 600 bar. Moreover, the mobile phase-B (acetonitrile $+0.1 \%$ formic acids) and " $A$ " (deionized water $+0.1 \%$ formic acid) instrumentally started from 15 and $85 \%$, respectively, and transported through the column by a stream of nitrogen gas after the column was injected with $5 \mu \mathrm{L}$ analyte solution.

\section{Sample Treatment and QuEChERS-dSPE Ionic Liquid-based DLLME Method}

The $250 \mathrm{~g}$ for each of the purchased vegetable (Petaling Jaya, Malaysia) samples of lettuce, garlic, ginger and bell-pepper were homogenized, and refrigerated (reserved) at $4{ }^{\circ} \mathrm{C}$. The methodological procedure occurred by transferring $20 \mathrm{~g}$ for each of the homogenized vegetable sample into $50 \mathrm{~mL}$ centrifuge tube and the content was spiked with $200 \mu \mathrm{L}$ of $100 \mu \mathrm{g} / \mathrm{kg}$ multipesticides mixture of standard solutions. 1\% HOAC in $15 \mathrm{~mL} A C N$ was added before covering and vortexing the tube for $1 \mathrm{~min}$. A sachet of QuEChERS extraction salt was added to the tube's content, covered, shaken vigorously (1 min) and centrifuged $(4000 \mathrm{rpm})$ for $2 \min .1 \mathrm{~mL}$ supernatant was transferred into $2 \mathrm{~mL}$ centrifuge tube that was occupied with a sachet of the cleanup agent. The tube was centrifuged (4000 rpm) for 5 min after vortexing it for $30 \mathrm{sec}$. Subsequently, the resulted supernatant from the d-SPE cleanup was transferred into $15 \mathrm{~mL}$ centrifuge tube containing $10 \% \mathrm{NaCl}$ in $9 \mathrm{~mL}$ of Milli-Q-water. The tube was covered, shaken vigorously ( $1 \mathrm{~min}$ ) and centrifuged (7000 rpm) for 5 min after addition of $130 \mu \mathrm{L}$ ionic liquid-based. Then, the $100 \mu \mathrm{L}\left[\mathrm{C}_{6} \mathrm{MIM}\right]\left[\mathrm{PF}_{6}\right]$ ionic liquid-based extract was diluted with $400 \mu \mathrm{L}$ of methanol (1:5) in $2 \mathrm{~mL}$ HPLC auto-sampler vial and vortexed for 1 min and the solution was analyzed with LC-MS/MS instrument. Consequently, the sum of the resulted total chromatographic peak areas (TCPAs) of the multiple reaction monitoring (MRM) scans for each of the analyte was used as an index that correspond to the concentration levels of analytes quantified in the analyzed samples (24).

Similarly, results were obtained for the construction of calibration curves and validation studies for each analyte respectively using parts of the refrigerated samples, weighed equally and spiked serially with estimated volumes of analyte mixture of standard solutions to provide equivalent known concentrations.

\section{Validation Studies of Sample Treatment Method}

The sample treatment method for the analysis of multiple pesticides residues was validated to express its effectivity, desirability and certification (25). The method was validated using the European Union Guideline (26) that include; accuracy (relative recovery) and precision (relative standard deviation) were estimated using triple concentration levels $(5,100$ and $300 \mu \mathrm{g} / \mathrm{kg}$ ) and the samples were analyzed in triplicates $(n=3)$, the limit of detections (LODs) and limit of quantitations (LOQs) were correspondingly estimated to 3 and 10 factors of signal-to-noise ratio respectively (27), the calibration curve for each analyte was used for the estimation of linearity based on the regression coefficient $\left(R^{2}\right)$ at five spiked concentration levels ranging $5-400 \mu \mathrm{g} / \mathrm{kg}$, the matrix effect (ME) was also estimated mathematically using the calibration curves (Equation 1) and ultimately, the empirical model and coverage factor $(k=2)$ were used for the estimation of measurement uncertainties (MU) at $95 \%$ confidence level (28).

$$
M E(\%)=\left[\left(\frac{\text { Slope of calibration curve for analyte in matrix }}{\text { Slope of calibration curve for analyte in ACN }}\right)-1\right] \times 100
$$

\section{RESULTS AND DISCUSSION}

The modified QuEChERS-dSPE Ionic Liquid-based DLLME method was successfully validated based on the parameters that include relative recoveries (RRs), relative standard deviations (RSDs), LODs, LOQS, R2, ME and MU. However, 98 and $99 \%$ of the RR $(87-127 \%)$ and RSDs $(3-22 \%)$ tabulated in Table 2 were within the recommended guideline $(70-120 \%)$ value (26) and conforms to the report of Nantia et al. (29). The range results of
$0.01-0.28$ and $0.03-0.93 \mu \mathrm{g} / \mathrm{kg}$ for LODs and LOQs (Table 3 ) respectively were excellent and lower that than the least concentration of the calibration curve $(5 \mu \mathrm{g} / \mathrm{kg})$ and European Union maximum residue limits (EU-MRLs) recommendation (30). The $\mathrm{R}^{2}$ obtained were linear and greater than 0.99 value as indicated in Table 4 . The results were similar to the documentation of Camino-Sánchez et al. (31) and Lawal et al. (32). Table 4 also shows that the method's performance capability (matrix effect) against matrix inferences towards recovery 
of analytes is very strong i.e. the matrix effects for all the analyzed samples were very weak, less effective ( $\leq-86)$ as referenced by the guideline; suppression $(-20 \%)$ or enhancement $(20 \%)$ of analytes' recovery, which could be attributed to the excessive cleanup of matrix interferences by the modified sample preparation method. Moreover, the matrix effect results were in line with the recent reports on the analysis of fruits and vegetables $(1,15,21)$. The recommended range $(50 \%)$ for the measurement uncertainties (MU) supported the obtained results (Table 4) range estimated $(1-25 \%)$. Eventually, the modified QuEChERS-dSPE Ionic Liquid-based DLLME sample treatment method coupled with the LC-MS/MS instrumentation were reliably and credibly used for quantitative analysis of the unspiked (reserved) vegetable samples and most of the analytes detected (Table 5) were lower than the LOQ and the EU-MRLs.

\section{CONCLUSION}

The determination of the multi-pesticide residues were successfully carried out in the samples of lettuce, garlic, ginger, and bell-pepper using modified QuEChERS-dSPE Ionic Liquid-based DLLME method. The extraction method efficiently cleanup the matrix interferences toward improving the detectability, selectivity and recovery of the targeted analytes using the sensitive instrument for better determination and recovery of the targeted analytes. Consequently, the sample preparation and instrumentation techniques proved reliable and successfully used for multi-residue determination of pesticides in lettuce, garlic, ginger, and bell-pepper samples. What is more, the obtained results for their concentration levels were less than the EU-MRLs, which presumed the safe consumption of the vegetables from the sampled area. 
Lawal A, Low KH. JOTCSA. 2021; 8(2): 693-704.

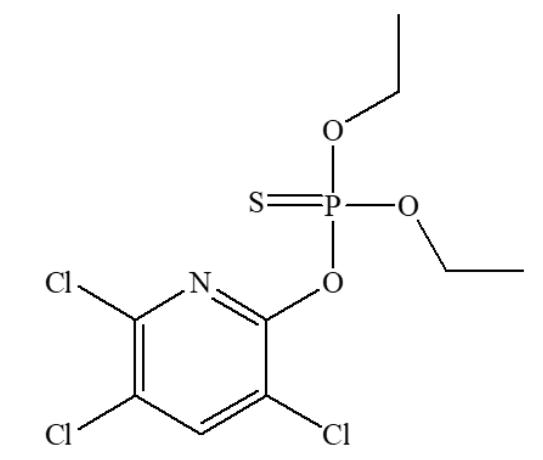

Dursban/Chlorpyrifos (Insecticide/Nematicide)

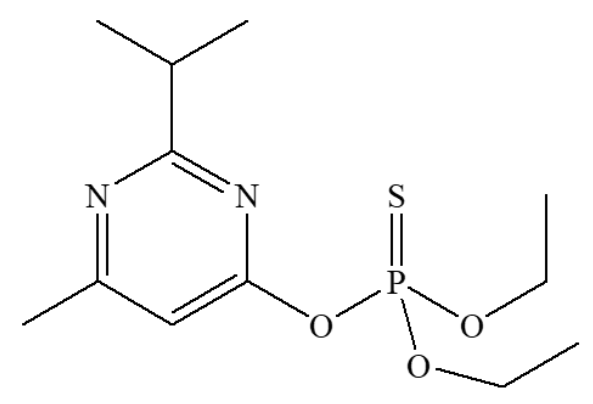

Diazinon (Insecticide)

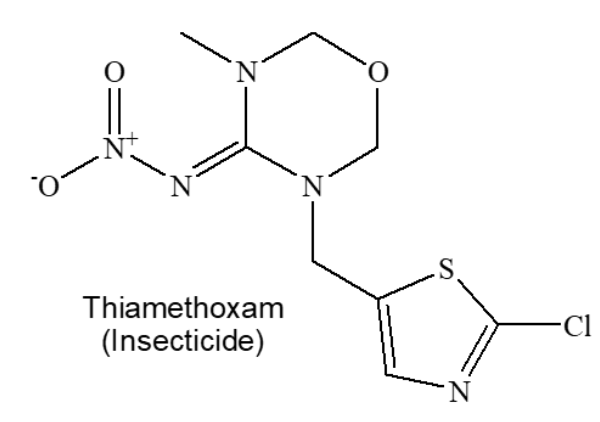

RESEARCH ARTICLE

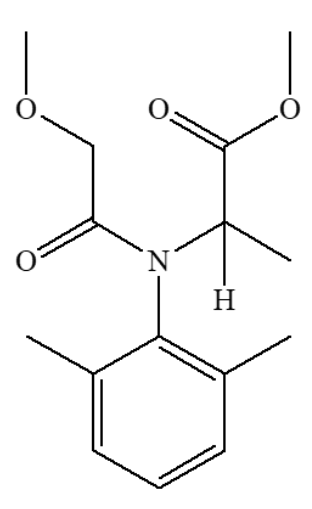

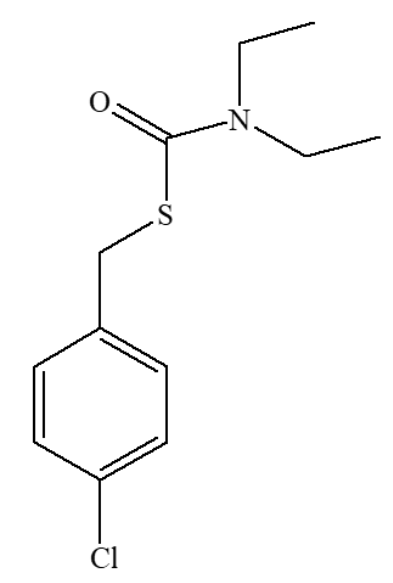

Thiobencarb/Benthiocarb (Herbicide)<smiles>CCC(C)c1ccccc1OC(=O)NC</smiles>

Baycarb/Fenobucarb (Insecticide)<smiles>CNC(=O)Oc1cccc2ccccc12</smiles>

Carbaryl

(Insecticide/Nematicide)<smiles>CCCOC(=O)NCCCN(C)C</smiles>

Propamocarb (Fungicide)

Figure 1: The Structures of the analyzed residue of pesticides 
Lawal A, Low KH. JOTCSA. 2021; 8(2): 693-704.

RESEARCH ARTICLE

\begin{tabular}{|c|c|c|c|c|c|c|c|c|}
\hline No. & Pesticides & $\begin{array}{l}\text { Molecular } \\
\text { Formula }\end{array}$ & Pesticide Type & $\begin{array}{l}\text { Ionization } \\
\text { Mode }\end{array}$ & $\begin{array}{c}\text { Precursor Ion, } \\
\mathrm{m} / \mathrm{z}\end{array}$ & $\begin{array}{l}\text { Product Ions } \\
\qquad(\mathrm{m} / \mathrm{z})\end{array}$ & $\begin{array}{c}\text { Collision Energies } \\
(\mathrm{eV})\end{array}$ & $\begin{array}{l}\mathrm{RT}_{1} ; \mathrm{RT}_{2} \\
(\mathrm{~min})\end{array}$ \\
\hline 8 & Dursban & $\mathrm{C}_{9} \mathrm{H}_{11} \mathrm{Cl}_{13} \mathrm{NO}_{3} \mathrm{PS}$ & Insecticide/Nematicide & {$[\mathrm{M}+\mathrm{H}]^{+}$} & 350 & $97 ; 198$ & $34 ; 22$ & $11.36 ; 11.36$ \\
\hline 7 & Diazinon & $\mathrm{C}_{12} \mathrm{H}_{21} \mathrm{~N}_{2} \mathrm{O}_{3} \mathrm{PS}$ & Insecticide & {$[\mathrm{M}+\mathrm{H}]^{+}$} & 305 & $97 ; 169$ & $42 ; 22$ & $10.22 ; 10.22$ \\
\hline 6 & Thiamethoxam & $\mathrm{C}_{8} \mathrm{H}_{10} \mathrm{ClN}_{5} \mathrm{O}_{3} \mathrm{~S}$ & Insecticide & {$[\mathrm{M}+\mathrm{H}]^{+}$} & 292 & $132 ; 211$ & $26 ; 10$ & $2.68 ; 2.68$ \\
\hline 5 & Metalaxyl & $\mathrm{C}_{15} \mathrm{H}_{21} \mathrm{NO}_{4}$ & Fungicide & {$[\mathrm{M}+\mathrm{H}]^{+}$} & 280 & $160 ; 220$ & $26 ; 10$ & $7.33 ; 7.33$ \\
\hline 4 & Thiobencarb & $\mathrm{C}_{12} \mathrm{H}_{16} \mathrm{CINOS}$ & Herbicide & {$[\mathrm{M}+\mathrm{H}]^{+}$} & 258 & $89 ; 125$ & $54 ; 26$ & $10.34 ; 10.34$ \\
\hline 3 & Baycarb & $\mathrm{C}_{12} \mathrm{H}_{17} \mathrm{NO}_{2}$ & Insecticide & {$[\mathrm{M}+\mathrm{H}]^{+}$} & 208 & $77 ; 95$ & $42 ; 10$ & $8.34 ; 8.34$ \\
\hline 2 & Carbaryl & $\mathrm{C}_{12} \mathrm{H}_{11} \mathrm{NO}_{2}$ & Insecticide/Nematicide & {$[\mathrm{M}+\mathrm{H}]^{+}$} & 202 & $127 ; 145$ & $30 ; 6$ & $7.16 ; 7.16$ \\
\hline 1 & Propamocarb & $\mathrm{C}_{9} \mathrm{H}_{20} \mathrm{~N}_{2} \mathrm{O}_{2}$ & Fungicide & {$[\mathrm{M}+\mathrm{H}]^{+}$} & 189 & $74 ; 102$ & $26 ; 14$ & $1.36 ; 1.36$ \\
\hline
\end{tabular}

No., identified pesticide analyte on the TIC chart 


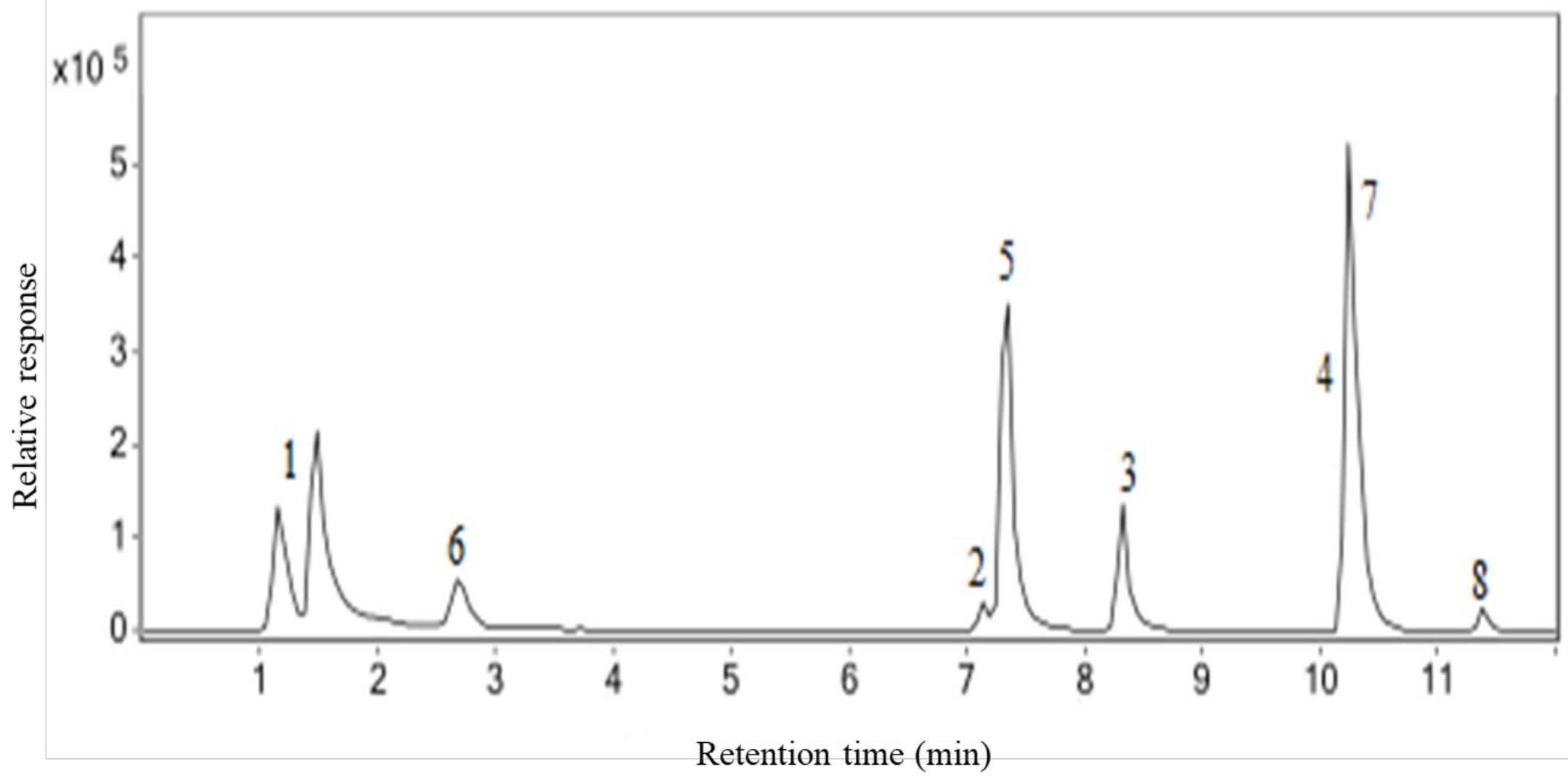

Figure 2: The TIC chart of the multi-pesticide analytes. 
Table 2: The accuracies, precisions at three concentration levels for the analyzed samples.

\begin{tabular}{|c|c|c|c|c|c|c|c|c|c|}
\hline \multirow[t]{2}{*}{ Pesticides } & \multirow[b]{2}{*}{ Spike $(\mu \mathrm{g} / \mathrm{kg})$} & \multicolumn{2}{|c|}{ Lettuce } & \multicolumn{2}{|c|}{ Garlic } & \multicolumn{2}{|c|}{ Ginger } & \multicolumn{2}{|c|}{ Bell-pepper } \\
\hline & & RR (\%) & RSD (\%) & RR (\%) & RSD (\%) & RR (\%) & RSD (\%) & RR (\%) & RSD (\%) \\
\hline \multirow[t]{3}{*}{ Durban } & 5 & 99 & 6 & 111 & 6 & 106 & 2 & 108 & 6 \\
\hline & 100 & 99 & 6 & 100 & 5 & 100 & 0 & 96 & 5 \\
\hline & 300 & 99 & 4 & 99 & 10 & 100 & 13 & 101 & 7 \\
\hline \multirow[t]{3}{*}{ Diazinon } & 5 & 100 & 4 & 103 & 5 & 99 & 2 & 105 & 4 \\
\hline & 100 & 101 & 4 & 97 & 7 & 101 & 4 & 99 & 3 \\
\hline & 300 & 100 & 6 & 97 & 4 & 101 & 4 & 99 & 4 \\
\hline \multirow[t]{3}{*}{ Thiamethoxam } & 5 & 111 & 7 & 103 & 7 & 100 & 2 & 91 & 4 \\
\hline & 100 & 102 & 4 & 99 & 2 & 104 & 1 & 99 & 3 \\
\hline & 300 & 99 & 5 & 99 & 8 & 96 & 1 & 100 & 5 \\
\hline \multirow[t]{3}{*}{ Metalaxyl } & 5 & 91 & 6 & 102 & 3 & 87 & 0 & 101 & 10 \\
\hline & 100 & 99 & 7 & 98 & 12 & 100 & 11 & 99 & 12 \\
\hline & 300 & 100 & 22 & 100 & 11 & 101 & 8 & 100 & 16 \\
\hline \multirow[t]{3}{*}{ Thiobencarb } & 5 & 88 & 11 & 100 & 7 & 102 & 5 & 91 & 3 \\
\hline & 100 & 100 & 4 & 102 & 8 & 101 & 3 & 101 & 4 \\
\hline & 300 & 101 & 5 & 98 & 1 & 101 & 3 & 98 & 3 \\
\hline \multirow{3}{*}{ Baycarb } & 5 & 112 & 4 & 106 & 2 & 124 & 0 & 102 & 2 \\
\hline & 100 & 99 & 5 & 101 & 3 & 99 & 0 & 100 & 3 \\
\hline & 300 & 100 & 5 & 97 & 2 & 99 & 1 & 100 & 4 \\
\hline \multirow[t]{3}{*}{ Carbaryl } & 5 & 95 & 6 & 101 & 6 & 94 & 1 & 98 & 3 \\
\hline & 100 & 101 & 6 & 99 & 4 & 99 & 4 & 100 & 2 \\
\hline & 300 & 100 & 4 & 99 & 8 & 99 & 15 & 101 & 11 \\
\hline \multirow[t]{3}{*}{ Propamocarb } & 5 & 106 & 6 & 106 & 5 & 127 & 3 & 92 & 5 \\
\hline & 100 & 101 & 3 & 99 & 4 & 101 & 1 & 103 & 5 \\
\hline & 300 & 100 & 4 & 100 & 2 & 99 & 17 & 100 & 3 \\
\hline Ranges & $5-300$ & $88-112$ & $3-22$ & $97-111$ & $1-12$ & $87-127$ & $0-17$ & $91-108$ & $2-16$ \\
\hline
\end{tabular}


Table 3: The pesticides detection and quantitation limits for the analyzed samples.

\begin{tabular}{|c|c|c|c|c|c|c|c|c|}
\hline & \multicolumn{2}{|c|}{ Lettuce } & \multicolumn{2}{|c|}{ Garlic } & \multicolumn{2}{|c|}{ Ginger } & \multicolumn{2}{|c|}{ Bell-pepper } \\
\hline & $\operatorname{LOD}(\mu \mathrm{g} / \mathrm{kg})$ & LOQ ( $\mu \mathrm{g} / \mathrm{kg})$ & LOD $(\mu \mathrm{g} / \mathrm{kg})$ & LOQ ( $\mu \mathrm{g} / \mathrm{kg})$ & LOD $(\mu \mathrm{g} / \mathrm{kg})$ & LOQ ( $\mu \mathrm{g} / \mathrm{kg})$ & LOD $(\mu \mathrm{g} / \mathrm{kg})$ & LOQ $(\mu \mathrm{g} / \mathrm{kg})$ \\
\hline Dursban & 0.05 & 0.17 & 0.08 & 0.28 & 0.01 & 0.03 & 0.11 & 0.37 \\
\hline Diazinon & 0.03 & 0.12 & 0.20 & 0.66 & 0.10 & 0.33 & 0.08 & 0.27 \\
\hline Thiamethoxam & 0.09 & 0.29 & 0.05 & 0.18 & 0.28 & 0.93 & 0.05 & 0.18 \\
\hline Metalaxyl & 0.05 & 0.17 & 0.08 & 0.26 & 0.08 & 0.27 & 0.04 & 0.13 \\
\hline Thiobencarb & 0.05 & 0.17 & 0.11 & 0.36 & 0.07 & 0.23 & 0.10 & 0.33 \\
\hline Baycarb & 0.02 & 0.07 & 0.16 & 0.53 & 0.06 & 0.21 & 0.03 & 0.09 \\
\hline Carbaryl & 0.05 & 0.15 & 0.07 & 0.22 & 0.10 & 0.32 & 0.04 & 0.12 \\
\hline Propamocarb & 0.06 & 0.19 & 0.02 & 0.07 & 0.10 & 0.33 & 0.07 & 0.23 \\
\hline Ranges & $0.02-0.09$ & $0.07-0.29$ & $0.02-0.20$ & $0.07-0.66$ & $0.01-0.28$ & $0.03-0.93$ & $0.03-0.11$ & $0.09-0.37$ \\
\hline
\end{tabular}

Table 4: The linearity of regression coefficient, matrix effects and measurement uncertainties for the analyzed samples.

\begin{tabular}{|c|c|c|c|c|c|c|c|c|c|c|c|c|}
\hline \multirow[t]{2}{*}{ Pesticides } & \multicolumn{3}{|c|}{ Lettuce } & \multicolumn{3}{|c|}{ Garlic } & \multicolumn{3}{|c|}{ Ginger } & \multicolumn{3}{|c|}{ Bell-pepper } \\
\hline & $\mathrm{R}^{2}$ & ME (\%) & MU (\%) & $\mathrm{R}^{2}$ & ME (\%) & MU (\%) & $\mathrm{R}^{2}$ & ME (\%) & MU (\%) & $\mathrm{R}^{2}$ & ME (\%) & MU (\%) \\
\hline Dursban & 0.9998 & -91 & 11 & 0.9996 & -98 & 14 & 0.9999 & -91 & 10 & 0.9994 & -86 & 12 \\
\hline Diazinon & 0.9999 & -97 & 9 & 0.9986 & -98 & 11 & 0.9996 & -100 & 7 & 0.9996 & -96 & 7 \\
\hline $\begin{array}{l}\text { Thiamethox } \\
\text { am }\end{array}$ & 0.9996 & -100 & 11 & 0.9998 & -100 & 11 & 0.9973 & -100 & 3 & 0.9999 & -100 & 8 \\
\hline Metalaxyl & 0.9999 & -99 & 23 & 0.9997 & -99 & 17 & 0.9998 & -100 & 13 & 0.9998 & -100 & 25 \\
\hline Thiobencarb & 0.9999 & -96 & 13 & 0.9995 & -98 & 11 & 0.9997 & -98 & 7 & 0.9996 & -93 & 7 \\
\hline Baycarb & 0.9998 & -98 & 9 & 0.9990 & -96 & 5 & 0.9996 & -97 & 1 & 0.9999 & -88 & 6 \\
\hline Carbaryl & 0.9999 & -100 & 11 & 0.9997 & -100 & 12 & 0.9996 & -100 & 13 & 0.9999 & -100 & 11 \\
\hline $\begin{array}{c}\text { Propamocar } \\
\text { b }\end{array}$ & 0.9998 & -100 & 9 & 0.9999 & -100 & 7 & 0.9994 & -100 & 14 & 0.9998 & -100 & 9 \\
\hline Ranges & $>0.999$ & $\leq-91$ & $\leq 23$ & $>0.99$ & $\leq-96$ & $\leq 17$ & $>0.99$ & $\leq-91$ & $\leq 14$ & $>0.999$ & $\leq-86$ & $\leq 25$ \\
\hline
\end{tabular}


Table 5: The pesticides residues in the analyzed samples.

\begin{tabular}{|c|c|c|c|c|c|c|c|c|}
\hline & \multicolumn{2}{|c|}{ Lettuce } & \multicolumn{2}{|c|}{ Garlic } & \multicolumn{2}{|c|}{ Ginger } & \multicolumn{2}{|c|}{ Bell-pepper } \\
\hline & $\mathrm{RC}(\mu \mathrm{g} / \mathrm{kg})$ & $\begin{array}{l}\text { EU-MRL } \\
(\mu \mathrm{g} / \mathrm{kg})\end{array}$ & $\mathrm{RC}(\mu \mathrm{g} / \mathrm{kg})$ & $\begin{array}{l}\text { EU-MRL } \\
(\mu \mathrm{g} / \mathrm{kg})\end{array}$ & $\mathrm{RC}(\mu \mathrm{g} / \mathrm{kg})$ & $\begin{array}{l}\text { EU-MRL } \\
(\mu \mathrm{g} / \mathrm{kg})\end{array}$ & $\mathrm{RC}(\mu \mathrm{g} / \mathrm{kg})$ & $\begin{array}{l}\text { EU-MRL } \\
(\mu \mathrm{g} / \mathrm{kg})\end{array}$ \\
\hline Dursban & $<\mathrm{LOQ}$ & 10 & $<\mathrm{LOQ}$ & 200 & $95.99 \pm 3.1$ & 3000 & $<\mathrm{LOQ}$ & 10 \\
\hline Diazinon & $<\mathrm{LOQ}$ & 50 & $<$ LOQ & 20 & $7.34 \pm 2.4$ & 10 & $<$ LOQ & 50 \\
\hline Thiamethoxam & $9.03 \pm 1.2$ & 20 & $<\mathrm{LOQ}$ & 10 & $178.30 \pm 7$ & 300 & $393 \pm 4.1$ & 700 \\
\hline Metalaxyl & $<\mathrm{LOQ}$ & 1000 & $<\mathrm{LOQ}$ & 500 & $13.41 \pm 1.0$ & 100 & $<\mathrm{LOQ}$ & 50 \\
\hline Thiobencarb & $<\mathrm{LOQ}$ & 100 & $8.50 \pm 2.5$ & 10 & $9.41 \pm 1.0$ & 10 & $<\mathrm{LOQ}$ & 10 \\
\hline Baycarb & $<\mathrm{LOQ}$ & 10 & $<\mathrm{LOQ}$ & 10 & $<\mathrm{LOQ}$ & 10 & $<\mathrm{LOQ}$ & 10 \\
\hline Carbaryl & $7.23 \pm 1.2$ & 10 & $12.06 \pm 1.1$ & 20 & $6.83 \pm 2.1$ & 10 & $8.29 \pm 2.5$ & 10 \\
\hline Propamocarb & $4.15 \pm 0.5$ & 700 & $<\mathrm{LOQ}$ & 2000 & $45.06 \pm 0.5$ & 50 & $<\mathrm{LOQ}$ & 3000 \\
\hline
\end{tabular}




\section{ACKNOWLEDGMENT}

The Postgraduate Research Project (IPPP), University of Malaya Kuala Lumpur, Malaysia (PG 174-2014B) is acknowledged for the support rendered.

\section{CONFLICT OF INTEREST}

The authors of this research agreed with no conflicts of interest.

\section{REFERENCES}

1. Lawal A, Koki IB. Determination of multi - pesticide residues in coconut water by QuEChERS - dSPE ionic liquid - based DLLME couple with high performance Liquid Chromatography - Tandem Mass Spectrometry (LCMS/MS). ChemSearch J. 2019;10(1):87-93. Url: https://www.ajol.info/index.php/csj/article/view/187964.

2. Koki IB, Lawal A, Taqui SN. Source identification and evaluation of surface water quality using factor and discriminant analysis. Bayero J Pure App Sci. 2019 May 9;11(2):169. Doi:

https://doi.org/10.4314/bajopas.v11i2.21.

3. Baba A, Garba ST, Bello HS. Bioremediation Potential of Immobilized corynebacterium kutsceri in the Treatment of Tannery Industrial Effluent from Challawa Industrial Estate, Kano State, Nigeria. Journal of the Turkish Chemical Society Section A: Chemistry. 2020 Mar 30;335-50. Doi: https://doi.org/10.18596/jotcsa.643771.

4. Lawal A. Comparative analysis on selected bulb species. Sokoto, Nigeria: Usmanu Danfodiyo University. 2011;

5. Slavin JL, Lloyd B. Health Benefits of Fruits and Vegetables. Advances in Nutrition. 2012 Jul 1;3(4):506-16. Doi: https://doi.org/10.3945/an.112.002154.

6. Özer Z. Chemical Composition and Antioxidant Activities of Leaf and Flower Essential Oils of Origanum onites $L$. Growing in Mount Ida-Turkey. JOTCSA. 2020 Oct 30;7(3):813-20. Doi: https://doi.org/10.18596/jotcsa.780334.

7. Lattimer JM, Haub MD. Effects of Dietary Fiber and Its Components on Metabolic Health. Nutrients. 2010 Dec 15;2(12):1266-89. Doi: https://doi.org/10.3390/nu2121266.

8. Lawal A, Matazu S. Comparative Studies of White and Red Allium cepa Cultivated in Sokoto, Nigeria. ChemSearch J. $2015 ; 6(2): 14-20$. Url: https://www.ajol.info/index.php/csj/article/view/130149.

9. Lawal A, Tan G, Alsharif A. Edibility and Medicinal Studies of Crinum ornatum inComparison with Allium sativum. Pakistan J Nutr. 2015;14(11):773-81.
10. Roth RA. Nutrition \& diet therapy. Eleventh edition. Clifton Park, NY: Delmar Cengage Learning; 2014. 604 p. Isbn: 978-1-133-96050-8.

11. Kaiser KA, Brown AW, Bohan Brown MM, Shikany JM, Mattes RD, Allison DB. Increased fruit and vegetable intake has no discernible effect on weight loss: a systematic review and meta-analysis. The American Journal of Clinical Nutrition. 2014 Aug 1;100(2):567-76. Doi: https://doi.org/10.3945/ajen.114.090548.

12. Esther G, Newark N. Dirt Poor: Have Fruits and Vegetables become Less Nutritious [Internet]. Scientific American; 2015. Available from:

http://www.scientificamerican.com/article/soil-depletionand-nutrition-loss/

13. Landsman J. The untold fruit and vegetable scandal [Internet]. Naturalhealth365.com; 2016. Available from: http://www.naturalhealth365.com/produce_scandal.html/

14. Kaur P, Bedi J, Sharma A, Gill J. Occurrence of Pesticide Residues in Water Collected from Different Water Sources in Punjab (India). Journal of Veterinary Public Health. 2016;12(2):75-9.

15. Lawal A, Wong RCS, Tan GH, Abdulra'uf LB, Alsharif AMA. Multi-pesticide Residues Determination in Samples of Fruits and Vegetables Using Chemometrics Approach to QuEChERS-dSPE Coupled with Ionic Liquid-Based DLLME and LC-MS/MS. Chromatographia. 2018 May;81(5):75968. Doi: https://doi.org/10.1007/s10337-018-3511-7.

16. Lawal A, Abdulra'uf LB. Chemometrics Approach to QuEChERS-dSPE for Multi-Standard Determination of Pesticides in Blank Samples of Milli-Q-Water Using HighPerformance Liquid Chromatography-Tandem Mass Spectrometry (LC-MS/MS). ChemSearch J. 2020;11(1):6673. Url: https://www.ajol.info/index.php/csj/article/view/197383.

17. Erdoğan G, Yilmaz İ. Determination of Some Pesticides Harmful To Environment and Human Health in Bogazköy(Turkey) Dam Water by LC-MS/MS. JOTCSA. 2020 Oct 18;801-12. Doi: https://doi.org/10.18596/jotcsa.749021.

18. Zhang $Y$, Zhang $Y$, Nie J, Jiao B, Zhao Q. Determination of Triazole Fungicide Residues in Fruits by QuEChERS Combined with Ionic Liquid-Based Dispersive Liquid-Liquid Microextraction: Optimization Using Response Surface Methodology. Food Anal Methods. 2016 Dec;9(12):350919. Doi: https://doi.org/10.1007/s12161-016-0548-9.

19. Lawal A, Wong RCS, Tan GH, Abdulra'uf LB, Alsharif AMA. Recent Modifications and Validation of QuEChERSdSPE Coupled to LC-MS and GC-MS Instruments for Determination of Pesticide/Agrochemical Residues in Fruits and Vegetables: Review. Journal of Chromatographic Science. 2018 Aug 1;56(7):656-69. Doi: https://doi.org/10.1093/chromsci/bmy032.

20. Lawal A, Tan GH, Alsharif AMA. Recent Advances in Analysis of Pesticides in Food and Drink Samples Using 
LPME Techniques Coupled to GC-MS and LC-MS: a Review. Journal of AOAC INTERNATIONAL. 2016 Nov

$1 ; 99(6): 1383-94$. Doi:

https://doi.org/10.5740/jaoacint.16-0272.

21. Lawal A, Wong RCS, Tan GH, Abdulra'uf LB. Determination of Pesticide Residues in Fruit and Vegetables by High-Performance Liquid Chromatography-Tandem Mass Spectrometry with Multivariate Response Surface Methodology. Analytical Letters. 2019 Jan 22;52(2):23148. Doi: https://doi.org/10.1080/00032719.2018.1459655.

22. Xie Q, Liu S, Fan Y, Sun J, Zhang X. Determination of phthalate esters in edible oils by use of QuEChERS coupled with ionic-liquid-based dispersive liquid-liquid microextraction before high-performance liquid chromatography. Anal Bioanal Chem. 2014 Jul;406(18):4563-9. Doi: https://doi.org/10.1007/s00216014-7814-8.

23. Gunatilake SR, Kwon J-W, Mlsna TE, Xia K. A novel approach to determine estrogenic hormones in swine lagoon wastewater using the QuEChERS method combined with solid phase extraction and LC/MS/MS analysis. Anal Methods. 2014 Sep 23;6(23):9267-75. Doi: https://doi.org/10.1039/C4AY01804D.

24. Abdulra'uf LB, Tan GH. Chemometric approach to the optimization of HS-SPME/GC-MS for the determination of multiclass pesticide residues in fruits and vegetables. Food Chemistry. 2015 Jun;177:267-73. Doi: https://doi.org/10.1016/j.foodchem.2015.01.031.

25. Li M, Dai C, Wang F, Kong Z, He Y, Huang YT, et al. Chemometric-assisted QuEChERS extraction method for post-harvest pesticide determination in fruits and vegetables. Sci Rep. 2017 Mar;7(1):42489. Doi: https://doi.org/10.1038/srep42489.

26. SANTE-11813. Guidance document on analytical quality control and method validation procedures for pesticide residues and analysis in food and feed. European Commission; 2017.

27. Xiu-ping $Z$, Lin $M$, Lan-qi $H$, Jian-Bo C, Li Z. The optimization and establishment of QuEChERS-UPLC-MS/MS method for simultaneously detecting various kinds of pesticides residues in fruits and vegetables. Journal of Chromatography B. 2017 Aug;1060:281-90. Doi: https://doi.org/10.1016/j.jchromb.2017.06.008.

28. Kaczyński P. Large-scale multi-class herbicides analysis in oilseeds by rapid one-step QuEChERS-based extraction and cleanup method using liquid chromatography-tandem mass spectrometry. Food Chemistry. 2017 Sep;230:41122. Doi: https://doi.org/10.1016/j.foodchem.2017.03.076.

29. Nantia EA, Moreno-González D, García-Campaña AM, Gámiz-Gracia L. High-Throughput Methodology for the Determination of Carbamates in Food Supplements by UHPLC-MS/MS. Chromatographia. 2017 Jan;80(1):63-70. Doi: https://doi.org/10.1007/s10337-016-3211-0.

30. Anonymous. Commission regulation. European Union; 2016.

31. Camino-Sánchez FJ, Zafra-Gómez A, Oliver-Rodríguez $B$, Ballesteros O, Navalón A, Crovetto G, et al. UNE-EN ISO/IEC 17025:2005-accredited method for the determination of pesticide residues in fruit and vegetable samples by LC-MS/MS. Food Additives \& Contaminants: Part A. 2010 Nov;27(11):1532-44. Doi: https://doi.org/10.1080/19440049.2010.506602.

32. Lawal A. Experimental Designs of QuEChERS-HexylMethylimidazolium Hexafluorophosphate Method Coupled With Liquid Chromatography-Mass Spectrometry for the Determination of Multiple Pesticides in Fruits and Vegetables [PhD THesis]. [Kuala Lumpur, Malaysia]: University of Malaya; 2018. 